\title{
ENRAIZAMENTO DE ESTACAS DE DUAS CULTIVARES DE OLIVEIRA SUBMETIDAS À APLICAÇÃO DE DIFERENTES FERTILIZANTES $\left({ }^{1}\right)$
}

\author{
MARCELO CAETANO DE OLIVEIRA $\left({ }^{2}\right)$; JOÃO VIEIRA NETO $\left({ }^{3}\right)$; RICARDO DE SOUZA OLIVEIRA $\left({ }^{2}\right)$; \\ RAFAEL PIO $\left({ }^{4 *}\right)$; NILTON CAETANO DE OLIVEIRA $\left({ }^{3}\right)$; JOSÉ DARLAN RAMOS $\left({ }^{4}\right)$
}

\begin{abstract}
RESUMO
Estacas semilenhosas com aproximadamente $12 \mathrm{~cm}$ de comprimento e quatro folhas coletadas na região mediana da copa em plantas de oliveira das cultivares Ascolano 315 e Arbequina, foram preparadas, e em seguida tratadas com $3000 \mathrm{mg} \mathrm{L}^{-1}$ de AIB por cinco segundos. O ensaio foi realizado em estufa, com sistema de nebulização intermitente, sendo as estacas colocadas em bandejas, contendo a perlite como substrato de enraizamento. Utilizando-se delineamento inteiramente casualizado, em esquema fatorial $2 \times 7$, com quatro repetições, avaliaram-se as duas cultivares de oliveira e seis fertilizantes (Biofertilizante, Nippoterra, Fert Bokashi e Ativo, na proporção de $25 \mathrm{~mL} \mathrm{~L}^{-1}$ e Nutricafé e Rocksil, na proporção de $25 \mathrm{~g} \mathrm{~L}^{-1}$ ), além do controle sem fertilizante. Os produtos foram aplicados nas parcelas experimentais antes da estaquia, com regador manual, em dosagem única. Passados 67 dias, foi avaliada a percentagem de estacas com calo e enraizadas e o número e comprimento médio das raízes. Concluiu-se que o Biofertilizante propiciou melhores resultados, em comparação aos demais fertilizantes e que a cultivar Ascolano 315 foi a que teve melhores taxas de enraizamento.
\end{abstract}

Palavras-chave: Olea europaea L., olivicultura, propagação, estaquia, nutrição.

\section{ABSTRACT \\ ROOTING OF CUTTINGS FROM TWO OLIVE CULTIVARS USING DIFFERENT FERTILIZERS}

Semi hardwood cutting colleted in the medium portion of the Ascolano 315 and Arbequina olive cultivars were prepared with $12 \mathrm{~cm}$ of length and four leaves, and treated with of IBA $\left(3,000 \mathrm{mg} \mathrm{L}^{-1}\right)$ by five seconds. The experiment was carried out in a greenhouse equipped with a mist nebulization system. Using a randomized experimental design in factorial scheme, in 4 replication, were tested the two cultivars and six fertilizers (Biofertilizante, Nippoterra, Fert Bokashi, Ativo, in the proportion of $25 \mathrm{~mL} \mathrm{~L}^{-1}$, Nutricafé and Rocksil, in the proportion of $25 \mathrm{~g} \mathrm{~L}^{-1}$ ) plus a control without fertilization. The products were applied in the trays contends perlite as substrate, in a unique dosage, defore cutting. After 67 days, the percentage of cutting with callus, rooted, number and lengh of rootses were evaluated. The Biofertilizante showed best results, in comparison to the other fertilizers, and the Ascolano 315 olive tree cultivar it presented best roots indexes.

Key words: Olea europaea L., oliviculture, propagation, cutting, nutrition.

( ${ }^{1}$ ) Recebido para a publicação em 16 de setembro de 2008 e aceito em 20 de outubro de 2009.

( $\left.{ }^{2}\right)$ Doutorando em Fitotecnia, Universidade Federal de Lavras, UFLA. Departamento de Agricultura, Caixa Postal 37, $37200-000$ Lavras (MG). E-mail: caetanocaldas@hotmail.com; oliveira@fundacaoroge.org.br

$\left({ }^{3}\right)$ Empresa de Pesquisa Agropecuária de Minas Gerais - EPAMIG, Bairro Vargedo, 35517-000 Maria da Fé (MG). E-mail: joaovieira@epamig.br; niltoncaetano@epamig.br

$\left({ }^{4}\right)$ Universidade Federal de Lavras, UFLA. Departamento de Agricultura, Caixa Postal 37, 37200-000 Lavras (MG). Bolsista Produtividade em Pesquisa CNPq. E-mail: rafaelpio@dag.ufla.br (*) Autor correspondente; darlan@ufla.br 
Atualmente, a multiplicação da oliveira é realizada através de estacas semilenhosas, dotadas de quatro folhas e enraizadas sob nebulização intermitente e com mecanismos que permitem o aquecimento do substrato (CABALlero e Del Rio, 2006). Esse sistema possibilitou avanços no enraizamento de estacas de oliveira. Entretanto, essa técnica obriga investimentos financeiros iniciais elevados, com a construção de instalações apropriadas.

Têm-se observado que a formação de raízes adventícias se deve à interação de fatores existentes nos tecidos da base da estaca e à translocação de substâncias sintetizadas nas folhas e gemas em desenvolvimento. Entre estes fatores, os reguladores de crescimento e os nutrientes minerais são de fundamental importância (WANG e ANDERSEN, 1989; Henry et al., 1992).

Como alguns nutrientes são essenciais à emissão das raízes nas estacas e alguns ainda participam como co-fatores no processo de enraizamento, como é o caso do boro e zinco, espera-se que uma fertilização suplementar ao substrato utilizado no enraizamento possa aumentar as taxas de enraizamento das estacas.

Quanto aos aspectos fisiológicos do enraizamento de estacas de oliveira, comprovou-se a necessidade da aplicação exógena de AIB e da conservação de folhas nas estacas (Avilan e LAVEe, 1978). Assim há necessidade de estudos mais aprofundados para se obter incrementos no potencial rizogênico das estacas de oliveira.

O presente trabalho foi realizado com o objetivo de quantificar, em estufa com nebulização intermitente, as taxas rizogênicas de estacas semilenhosas de duas cultivares de oliveira submetidas à aplicação de diferentes fertilizantes orgânicos no substrato de enraizamento.

Estacas semilenhosas foram coletadas em, setembro de 2007, na região mediana em torno da copa, em plantas de oliveiras 'Ascolano 315' e 'Arbequina' de oito anos de idade, pertencentes ao banco de germoplasma da EPAMIG. Foram preparadas com aproximadamente $12 \mathrm{~cm}$ de comprimento, diâmetro de $4 \mathrm{~mm}$ e com quatro entrenós, mantendo quatro folhas nos dois primeiros entrenós. Foi realizado um corte reto no ápice e outro em bisel na base da estaca, que foram imersas por cinco segundos em solução de AIB (3000 mg L $\left.{ }^{-1}\right)$, conforme as recomendações de Oliveira et al. (2009).

O ensaio foi realizado em estufa, com sistema de nebulização intermitente (automatizada por um temporizador regulado para acionar às $6 \mathrm{~h}$ e desligar às $22 \mathrm{~h}$, com nebulizações acionadas a cada cinco minutos por um período de 10 segundos), sendo o estaqueamento feito em bandejas plásticas, a uma profundidade de 4 centímetros, utilizando como substrato a perlita.

Antes do estaqueamento, foram aplicados os seguintes fertilizantes orgânicos: Biofertilizante, Nippoterra, Fert Bokashi, Ativo (diluído a $25 \mathrm{~mL} \mathrm{~L}^{-1}$ ), Nutricafé e Rocksil (diluído a $25 \mathrm{~g} \mathrm{~L}^{-1}$ ). A porcentagem em nutrientes nestes fertilizantes, coletados na bula dos produtos, é apresentada na tabela 1 . Os produtos foram aplicados nas parcelas experimentais com regador manual, em dosagem única. Cada parcela tinha dimensão de $1 \times 0,16 \times 0,2 \mathrm{~m}$, com 32 litros de perlite, sendo regada com $2 \mathrm{~L}$ de solução.

O delineamento utilizado foi o inteiramente casualizado, em esquema fatorial $2 \times 7$, avaliando-se as duas cultivares de oliveira e os seis fertilizantes, além de controle (ausência de tratamento), com quatro repetições e a parcela constituída por 25 estacas. Passados 67 dias, foi avaliada a percentagem de estacas com calo, a percentagem de estacas enraizadas, o número e o comprimento médio das raízes.

Os dados recolhidos foram analisados estatisticamente, utilizando o programa SISVAR. As porcentagens de estacas com calo e estacas enraizadas, foram transformadas por arc sen $(x / 100)^{1 / 2}$, com a finalidade de proporcionar a normalidade dos erros.

De acordo com a análise estatística, não houve efeito da interação entre cultivares e fertilizantes, sendo os efeitos isolados destes fatores para os diferentes parâmetros avaliados, apresentados nas tabelas 2 e 3 .

Apesar de não ter havido diferença entre a taxa de calejamento das estacas das diferentes cultivares, a oliveira 'Ascolano 315' proporcionou melhor desempenho no enraizamento de estacas, 6,3\% superior a 'Arbequina' e o comprimento médio das raízes foi $21 \%$ superior (Tabela 2). Por se tratar de valores médios de diferentes tratamentos com fertilizantes, incluindo o controle no qual não houve emissão de raízes, as taxas são bastante inferiores ao relatado por Pio et al. (2005), que obtiveram $45,81 \%$ de enraizamento em estacas semilenhosas com um par de folhas de oliveira 'Grapollo' tratadas com AIB, em sistema de nebulização intermitente.

Quanto à aplicação dos fertilizantes ao substrato, o Biofertilizante, Nippoterra, Ativo e Nutricafé Proporcionaramaos melhores resultados para a porcentagem de estacas calejadas (Tabela 3). Analisando-se a tabela 1, verifica-se que os quatro fertilizantes mencionados são os únicos que possuem em sua composição o zinco, elemento imprescindível para a melhoria da rizogênese em estacas. 
Tabela 1. Porcentagem de nutrientes em cada fertilizante utilizados no referido trabalho.Maria da Fé (MG), 2008

\begin{tabular}{|c|c|c|c|c|c|c|}
\hline \multirow{2}{*}{ Nutriente } & \multicolumn{6}{|c|}{ Porcentagem de nutrientes em cada fertilizante } \\
\hline & Biofertilizante & Nippoterra & Fert Bokashi & Ativo & Nutricafé & Rocksil \\
\hline & & & $\%$ & 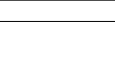 & 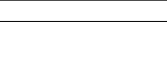 & 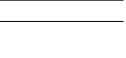 \\
\hline $\mathrm{N}$ & - & 8,00 & 1,00 & - & - & - \\
\hline $\mathrm{P}$ & - & 6,00 & - & - & - & 0,10 \\
\hline $\mathrm{K}$ & 0,10 & 15,00 & - & - & 10,00 & - \\
\hline $\mathrm{Zn}$ & 0,34 & 0,20 & - & 1,00 & 5,00 & - \\
\hline $\mathrm{Cu}$ & 0,02 & 0,05 & - & 0,30 & 10,00 & - \\
\hline $\mathrm{Fe}$ & - & 0,20 & - & 0,50 & - & 0,16 \\
\hline $\mathrm{Mn}$ & 0,04 & 0,50 & - & 0,50 & 2,00 & - \\
\hline B & 0,18 & 0,40 & - & 0,50 & 3,00 & - \\
\hline Co & - & - & - & - & - & - \\
\hline Mo & 0,43 & 0,05 & - & 0,10 & - & - \\
\hline S & 0,12 & - & - & 2,00 & 10,00 & 9,82 \\
\hline $\mathrm{Mg}$ & - & - & - & 1,00 & 1,00 & 0,18 \\
\hline $\mathrm{Al}$ & - & - & - & - & - & 20,56 \\
\hline $\mathrm{Si}$ & - & - & - & - & - & 17,43 \\
\hline $\mathrm{Ca}$ & 0,64 & - & - & - & - & 1,31 \\
\hline $\mathrm{Ti}$ & - & & - & - & - & 0,34 \\
\hline C orgânico & 0,27 & - & 8,00 & - & - & - \\
\hline
\end{tabular}

Fonte: bula dos produtos.

Tabela 2. Porcentagem de estacas com calo, porcentagem de estacas com calo, número médio de raízes e comprimento médio das raízes em estacas de duas cultivares de oliveira (Olea europaea L.). Maria da Fé (MG), 2008

\begin{tabular}{|c|c|c|c|c|}
\hline Cultivares & Estacas com calo & Estacas com calo & Média de raízes & Comprimento médio das raízes \\
\hline & \multicolumn{2}{|c|}{$\%$} & n. ${ }^{\circ}$ & $\mathrm{cm}$ \\
\hline Ascolano 315 & 15,8 a & 19,0 a & $2,6 \mathrm{a}$ & $2,3 \mathrm{a}$ \\
\hline Arbequina & 14,4 a & $12,7 \mathrm{~b}$ & $2,4 \mathrm{a}$ & $1,9 \mathrm{~b}$ \\
\hline CV (\%) & 32,33 & 33,24 & 44,78 & 26,71 \\
\hline
\end{tabular}

Médias seguidas pela mesma letra na coluna não diferem significativamente entre si, pelo teste F, ao nível de 5\% de probabilidade.

Tabela 3. Percentagem de estacas com calo, percentagem de estacas com calo, número médio de raízes e comprimento médio das raízes em estacas de oliveira (Olea europaea L.) submetidas a aplicação de diferentes fertilizantes durante a rizogênese. Maria da Fé (MG), 2008

\begin{tabular}{|c|c|c|c|c|}
\hline Fertilizante & Estacas com calo & Estacas com calo & Média de raízes & Comprimento médio das raízes \\
\hline & \multicolumn{2}{|c|}{$\%$} & n..$^{\circ}$ & $\mathrm{cm}$ \\
\hline Controle & $6,5 \mathrm{~b}$ & $0 \mathrm{c}$ & $0 \mathrm{~d}$ & $0 \mathrm{~d}$ \\
\hline Biofertilizante & 21,0 a & 54,5 a & $4,5 \mathrm{a}$ & $4,8 \mathrm{a}$ \\
\hline Nipoterra & 15,5 a & $22,5 \mathrm{~b}$ & $4,2 \mathrm{a}$ & $3,7 \mathrm{~b}$ \\
\hline Fert Bokashi & $9,5 \mathrm{~b}$ & $2,0 \mathrm{C}$ & $1,1 \mathrm{c}$ & $0,4 \mathrm{~d}$ \\
\hline Ativo & $20,5 \mathrm{a}$ & $21,0 \mathrm{~b}$ & $2,9 \mathrm{~b}$ & $3,5 \mathrm{~b}$ \\
\hline Nutricafé & 25,5 a & $7,5 \mathrm{c}$ & $2,9 \mathrm{~b}$ & $1,2 \mathrm{c}$ \\
\hline Rocksil & $6,3 \mathrm{~b}$ & $2,3 \mathrm{c}$ & $1,8 \mathrm{c}$ & $1,2 \mathrm{c}$ \\
\hline $\mathrm{CV}(\%)$ & 32,33 & 33,24 & 44,78 & 26,71 \\
\hline
\end{tabular}

* Médias seguidas pela mesma letra na coluna não diferem significativamente entre si, pelo teste F, ao nível de 5\% de probabilidade. 
O zinco é requerido na síntese do triptofano, um precursor do AIA, Ácido Indol-3 Ácético, que é um fito-hormônio envolvido na formação de raízes adventícias (Mengel e KirKby, 1979; BlaKesley et al., 1991).

No entanto, as estacas tratadas com os Biofertilizante Ativo e Nutricafé, tiveram elevado índice de calejamento $(20,5 \%$ e $25,5 \%)$, mas não ocorreram altas taxas para a percentagem de estacas enraizadas (21\% e 7,5\%) (Tabela 3). Apesar de os mesmos possuírem o zinco em suas composições, esses Biofertilizantes possuem 1\% e 5\% de zinco (Tabela 1). Possivelmente, o excesso de zinco pode ter promovido efeito inibitório ao enraizamento.

O triptofano tem origem no ciclo do ácido shiquímico (FREGONI, 1985) e forma auxinas endógenas via ácido indolpirúvico, triptamina e indolacetoaldoxima (Coll et al., 1990). A conversão via ácido indolpirúvico é feita por transaminação (TRuelsen, 1973). Cita-se também, que há possibilidade de transformação de L-triptofano em ácido indolacético via indolacetoaldoxima (LUDWIG-MÜLLER e Hilgenberg, 1988). Tanto a forma " $L$ " como a " $\mathrm{D}$ " triptofano podem ser precursoras de ácido indolacético. Porém o maior efeito da forma Dtriptofano induz a suposição de que este é o precursor mais direto.

Quanto à porcentagem de estacas enraizadas, o Biofertilizante foi o que proporcionou o melhor resultado (54,5\%) (Tabela 3). A superioridade desse fertilizante, em relação aos demais, pode estar relacionada à presença de carbono orgânico em sua composição $(0,27 \%)$, no entanto, em níveis aceitáveis, em relação ao Fert Bokashi, que possui $8 \%$ em sua composição. Por meio de estudos, constata-se a necessidade de um determinado equilíbrio entre a auxina e hidratos de carbono para a ótima produção de raízes, visto que, durante o processo de enraizamento, ocorrem contínuas perdas de amido e açúcares solúveis na base da estaca, que comporta um forte dreno de assimilados. De acordo com HARTMANN et al. (2002), há uma relação entre o potencial de enraizamento e o conteúdo de hidratos de carbono presentes nas estacas de algumas espécies, inclusive para oliveira (Rallo e Del Rio, 1990; Del Rio e CABallero, 1991).

Para o número médio de raízes, os fertilizantes Nippoterra e Biofertilizante proporcionaram melhores resultados (4,2 e 4,5 raízes respectivamente), ocorrendo também com esse último o maior comprimento das raízes formadas (Tabela 3). Essa superioridade do Biofertilizante pode estar relacionada aos níveis adequados de boro em sua composição $(0,18 \%$ - Tabela 1). Têm-se observado que a deficiência de boro proporciona distúrbios ao desenvolvimento dos tecidos meristemáticos, como morte dos ápices das raízes e tecidos do câmbio (Mengel e KiRKBY, 1979). A iniciação de raízes nas estacas é estimulada pela auxina, devendo-se o posterior crescimento ao boro (MiddLEton et al., 1978). Henry et al. (1992) observaram correlação significativa entre níveis de boro observados nas estacas de Juniperus virginiana L. e a resposta ao enraizamento.

Pesquisas com enraizamento da cultivar Ascolano 315 indicam capacidade de enraizamento em torno de $30 \%$, tanto sem o uso de instalações com controle ambiental (Oliveira et al., 2003), quanto com o emprego de câmara de nebulização com substrato aquecido (Oliveira et al., 2006). No presente estudo, com a utilização do Biofertilizante e adotando-se a utilização de câmara de nebulização intermitente sem aquecimento do substrato, o índice isolado de enraizamento das estacas daquela cultivar foi de $65 \%$, ou seja, $116 \%$ superior aos valores obtidos nos trabalhos mencionados.

Wiesman e LAVEes (1995) comprovaram que a aplicação de solução de AIB juntamente com uréiafosfato aumentou a eficiência rizogênica das estacas e sua sobrevivência. Há indícios de incrementos significativos na emissão de raízes em estacas de oliveira que receberam tratamentos com fertilizantes, no entanto, devem-se aprofundar os estudos visando aumentar o rendimento de mudas obtidas pela propagação por estacas.

Os resultados indicam potencial do Biofertilizante para uso em enraizamento de estacas de oliveira, podendo auxiliar na redução dos custos de produção das mudas.

\section{REFERÊNCIAS}

AVILAN, B.; LAVEE, S. Physiological aspects of the rooting ability of olive cultivars. Acta Horticulturae, v.102, p.7993, 1978.

BLAKESLEY, D.; WESTON, G.D.; HALL, J.F. The role of endogenous auxin in root initiation. Plant Growth Regulation, v.10, p.341-353, 1991.

CABALLERO, J.M.; DEL RÍO, C. Propagação da oliveira por enraizamento de estacas semi-lenhosas sob nebulização. Informe Agropecuário: v.27, p.33-38, 2006.

COOL, J.B.; RODRIGO, G.N.; GARCIA, B.S.; TAMÉS, R.S. Fisiologia Vegetal. Madri, 1990. 824p.

DEL RIO, C.; CABALLERO, J.M. Effects of carbohydrate content on the seasonal rooting of vegetive and reproductive cuttings of olive. Journal of Horticultural Science, v.66, p.301-309, 1991. 
FREGONI, M. Viticultura Generale. Roma: Reda, 1985. 726 p.

HARTMANN, H.T.; KESTER, D.E.; DAVIES JUNIOR, F.T.; GENEVE, R.L. Plant propagation: principles and practices. 7. ed. New Jersey: Prentice Hall, 2002. 880 p.

HENRY, P.A.; BLAZICH, F.A.; HINESLEY, L.E. Influence of stock fertility on adventicious rooting of stem cuttings. Journal of American Society for Horticultural Science, v.117, p. 568570, 1992.

LUDWIG-MULLER, J.;HILGENBERG, W. A plasma membranebound enzyme oxidizes L-tryptophan to indole- 3acetaldoxime. Physiologia Plantarum, v.74, p.240-250, 1988.

MENGEL, K.; KIRKBY, E.A. Principles of plant nutrition. Worblaufer-Bern: International Potash Institute, 1979. 579p.

MIDDLETON, W.; JARVIS, B.C.; BOOTH, A. The boron requirement for roots development in stem cutting of Phaseolus aureus Roxb. New Phytologist, v. 81, p. 287-291, 1978.

OLIVEIRA, A.F.; ALVARENGA, A.A.; CHALFUN, N.N.J.; GONÇALVES, F.S. Enraizamento de estacas semi-lenhosas de oliveira em câmara úmida com aquecimento de substrato. Informe Agropecuário: v.27, p.40-46, 2006.

OLIVEIRA, A.F.; PASQUAL, M.; CHALFUN, N.N.J.; REGINA, M.A.; RINCÓN, C.D.R. Enraizamento de estacas semi-lenhosas de oliveira sob efeito de diferentes épocas, substratos e concentrações de ácido indolbutírico. Ciência e Agrotecnologia, v.27, p.117-125, 2003.

OLIVEIRA, A.F.; CHALFUN, N.N.J.; ALVARENGA, A.A.; VIEIRA NETO, J.; PIO, R.; OLIVEIRA, D.L. Estaquia de oliveira em diferentes épocas, substratos e doses de AIB diluídos em NAOH e álcool. Ciência e Agrotecnologia, v.33, p.79-85, 2009.

PIO, R.; BASTOS, D.C.; BERTI, A.J.; SCARPARE FILHO, J.A.; MOURÃO FILHO, F.A.A.; ENTELMANN, F.A.; ALVES, A.S.R.; BETTIOL NETO, J.E. Enraizamento de diferentes tipos de estacas de oliveira (Olea europaea L.) utilizando-se ácido indolbutírico. Ciência e Agrotecnologia, v.29, p.562-567, 2005.

RALLO, L.; DEL RIO, C. Effect of a CO2 enriched environment on the rooting ability and carbohydrate level of olive cuttings. Advances in Horticultural Science, v.4, p.129-130, 1990.

TRUELSEN, T.A Indole-3-piruvic acid as an intermediate in the conversion of tryptophan to indole-3-acetic acid. II Distribuition of tryptophan transaminase activity in plants. Physiologia Plantarum, v.28, p.67-70, 1973.

WANG, Q.; ANDERSEN, A.S. Propagation of Hibiscus rosasinensis: relations between stock plant cultivar, age, environment and growth regulator treatments. Acta Horticulturae, v.245, p.289-309, 1989.

WIESMAN Z.; LAVEES. Enhancement of IBA stimulatory effect on rooting of olive cultivar stem cuttings. Scientia Horticulturae, v.62, p.189-198, 1995. 